\title{
Flame Retardancy Enhancement of Hybrid Composite Material by Using Inorganic Retardants
}

\author{
Mohammed Al-Maamori ${ }^{1}$, A. Al-Mosawi ${ }^{2}$, Abbass Hashim ${ }^{3 *}$ \\ ${ }^{1}$ Faculty of Material Engineering, University of Babylon, Babylon, Iraq; ${ }^{2}$ Department of Mechanical Engineering, Technical Institute, \\ Babylon, Iraq; ${ }^{3}$ Materials and Engineering Research Institute, Sheffield Hallam University, Sheffield, S1 1WB, UK \\ Email: a.hashim@shu.ac.uk
}

Received January $18^{\text {th }}, 2011$; revised March $22^{\text {nd }}, 2011$; accepted May $24^{\text {th }}, 2011$

\begin{abstract}
This study aims to investigate the possibility of improving the flame Retardancy for the hybrid composite material consisting araldite resin (CY223). The hybrid composite was reinforced by hybrid fibers from carbon and Kevlar fibers on woven roving form $\left(0^{\circ}-4^{\circ}\right)$, by using a surface layer of $4 \mathrm{~mm}$ thick of Zinc Borate flame retardant. Afterward, the structure was exposed directly to gas flame of $2000^{\circ} \mathrm{C}$ due to $10 \mathrm{~mm}$ and $20 \mathrm{~mm}$ exposure interval. The retardant layer thermal resistance and protection capability were determined. The study was continued to improve the performance of Zinc Borate layer mixed by 10\%, 20\% and 30\% of Antimony Trioxide. To determine the heat transfer of the composite material the opposite surface temperature method was used. Zinc Borate with (30\%) Antimony Trioxide gives the optimized result of the experiment.
\end{abstract}

Keywords: Hybrid Composite Material, Flame Retardant Material, Inorganic Retardant

\section{Introduction}

Fire safety is an integral part of precautions having an objective to minimize the damage from measuring hindering their initiation, limiting their propagation and the possibility of excluding flash-over. Preventing fires or delaying them makes escape possible over a longer period of time. As a result, life, health, and property are efficiently protected [1].

Plastics are synthetic organic materials with carbon and high hydrogen contents, they are most likely combustible. For various applications in the building, electrical, transportation and other industries, plastics have to fulfill flame retardancy requirements laid down in mandatory regulation and voluntary specification. The objective of flame retarding polymers is to increase ignition resistance and reduce rate of flame spread [2].

One of the ways for better protect combustible materials against initiating fires is the use of flame retardants. This substance can be chemically inserted into the polymer molecule or physically blended in polymers after polymerization. This will suppress, reduce, delay or modify the propagation of the flame through plastic materials.
There are several classes of flame retardants; halogenated hydrocarbons (chlorine and bromine containing compounds and reactive flame retardants), inorganic flame retardants (boron compounds, antimony oxides, aluminum hydroxide, etc) and phosphorus compounds flame retardants containing nitrogen. Depending on their nature, flame retardants can act physically or chemically [3].

\section{Flame Retardant Materials}

Flame retardants are substances used in plastics, textiles, electronic circuitry and other materials to prevent fires. There are several types of flame retardants as mentioned above, one of these types is inorganic flame retardants. Few inorganic compounds are suitable for use as flame retardants in plastics, since such compounds must be effective in the range of decomposition temperature of the plastic, mainly $\left(150^{\circ} \mathrm{C}-400^{\circ} \mathrm{C}\right)$. Inorganic flame retardants don't evaporate under the influence of heat rather they decompose giving off non-flammable gases like water, carbon dioxide, sulphur dioxide and hydrogen chloride. Endothermic reaction in the gas phase acts by 
diluting the mixture of flammable gases and by shielding the surface of the polymer against oxygen attack [4].

The inorganic flame retardants are performed simultaneously on the surface of the solid phase by cooling the polymer via endothermic breakdown process and reducing the formation of pyrolysis products. In addition as in the case of inorganic boron compounds, a glassy protective layer can form on the substrate fending off the effect of oxygen and heat [5]. As example to inorganic flame retardants is zinc borate, aluminum hydroxide, magnesium hydroxide and antimony oxides.

Zinc borate is an effective inorganic flame retardant possessing the characteristic properties of smoke suppression and promoting charring which is particularly important according to new fire standards. Zinc borate is commonly used as multifunctional flame retardant in combination with other halogenated or halogen free flame retardant systems to boost FR properties. Its efficacy depends upon the type of halogen source (aliphatic versus aromatic) and the used polymer. The zinc borate can generally display synergistic effects with antimony oxide in fire retardancy [6]. Table 1 shows the characterizations and properties of zinc borate.

Antimony trioxide (ATO) has white color or colorless depended on its structure. ATO dissolved slightly in water and dissolved in potassium hydroxide, dilute hydrochloric acid and with many organic acids [4]. Table 2 shows the properties of ATO. Figure 1 shows the chemical structure of ATO.

\section{Composite Materials}

Composite material is a material consisting of two or more physically and (or) chemically distinct phase suitably arranged or distributed. The composite material usually has characteristics that are not depicted by any of its components in isolation [6]. Generally, the composite material contains two elements:

1) Material matrix: it is the continuous phase of metal, ceramic or polymer. The polymer matrix is considered the best because of its mechanical and thermal properties and also it can reinforce by a large fiber volume fraction compared with metal and ceramic matrix. The polymer matrix is low cost and easy fabrication, e.g. araldite resin, polyester, and epoxy resin. Araldite resin belongs to epoxy group which has excellent thermal and physical properties and usually used in composite materials for different applications. Epoxy group distinct by excellent adhesive capability especially to fibers and retains constant dimensions after dryness [7].

2) Material reinforce: the distributed phase is called reinforcement; many reinforcement materials are available in a variety of forms, e.g. continuous fibers, short fibers, whiskers, particles...etc. Reinforcements include organic fibers such as carbon and Kevlar fibers, metallic fibers, ceramic fibers and particles [8].

High strength and high modulus carbon fibers are of about $(7-8 \mu \mathrm{m})$ in diameter and consist of small crystallites of Turbostratic graphite, one of the allotropic forms of carbon [9].

Kevlar is an organic Aramid fiber with (3100 MPa) tensile strength and (131,000 MPa) elastic modulus. Kevlar density is approximately one-half of aluminum and good toughness [10].

\section{Experimental Work}

\section{Materials}

There are three types of materials implemented in this study:

1) Flame retardant material:

a) Zinc Borate $2335\left(2 \mathrm{ZnO} .3 \mathrm{~B}_{2} \mathrm{O}_{3} \cdot 5 \mathrm{H}_{2} \mathrm{O}\right)$ was used as a flame retardant supplied by $\mathrm{C}$-Tech corporation. Table 3 shows the chemical composition of Zinc Borate.

Antimony Trioxide $\left(\mathrm{Sb}_{2} \mathrm{O}_{3}\right)$ supplied by BDH Chemical Ltd Pool England) with particle size $2 \mu$.

2) Matrix material; Araldite resin (CY223) with density of $\left(1.15-1.2 \mathrm{~g} / \mathrm{cm}^{3}\right)$ belong to epoxies group was used in this study. Figure 2 shows the chemical structure of Araldite resin.

3) Reinforce fibers: two types of fibers were used as consecutive layers in same matrix:

a) Carbon fibers, woven roving fibers $\left(0^{\circ}-45^{\circ}\right)$, with density of $\left(1.75 \mathrm{~g} / \mathrm{cm}^{3}\right)$.

b) Kevlar fibers, woven roving fibers $\left(0^{\circ}-45^{\circ}\right)$, with density of $\left(1.45 \mathrm{~g} / \mathrm{cm}^{3}\right)$.

Figure 3 shows the chemical structure of Kevlar fibers.

Table 1. Characterizations and properties of zinc borate [3].

\begin{tabular}{cccccc}
\hline Mol Wt & PH & Density g/ $/ \mathrm{cm}^{3}$ & Melting Point ${ }^{\circ} \mathrm{C}$ & Appearance & Property \\
\hline 434.62 & 7.6 & 3.64 & 980 & White Crystalline & Value \\
\hline
\end{tabular}

Table 2. properties of antimony trioxide [4].

\begin{tabular}{cccc}
\hline Density $\left(\mathrm{g} / \mathrm{cm}^{3}\right)$ & Boiling Point $\left({ }^{\circ} \mathrm{C}\right)$ & Melting Point $\left({ }^{\circ} \mathrm{C}\right)$ & Property \\
\hline 5.67 & 1425 & 656 & Value \\
\hline
\end{tabular}




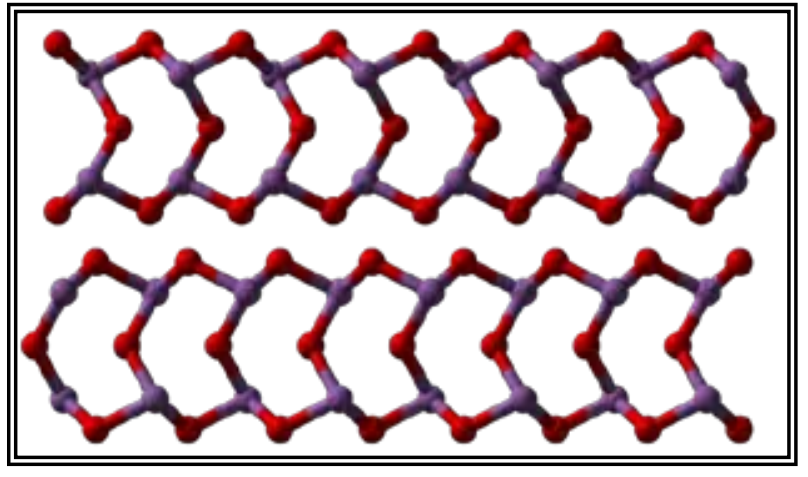

Figure 1. Chemical structure of ATO.

\subsection{Samples Preparation}

The samples of thermal erosion test are squared shape with dimensions of $100 \times 100 \mathrm{~mm}^{2}$ and $10 \mathrm{~mm}$ thick consisting two layers as shown in Figure 4.

a-Flame retardant Zinc Borate layer with $4 \mathrm{~mm}$ thick.

Composite of carbon and Kevlar fiber layer of $6 \mathrm{~mm}$ thick used as consecutive layers in araldite resin.

\subsection{Thermal Erosion Test}

Flame generated from butane-propane gas $\left(\mathrm{C}_{3} \mathrm{H}_{8}-\mathrm{C}_{4} \mathrm{H}_{10}\right)$ with temperature of $2000^{\circ} \mathrm{C}$ was used. The structure contains flame retardant material and composite material exposed to this temperature with exposure intervals of 10<smiles>CCC(O)COc1ccc(C(C)(C)c2ccccc2)cc1</smiles>

Figure 2. Chemical structure of Araldite resin.

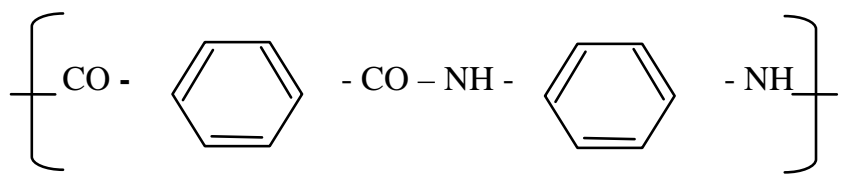

Figure 3. chemical structure of Kevlar fibers.

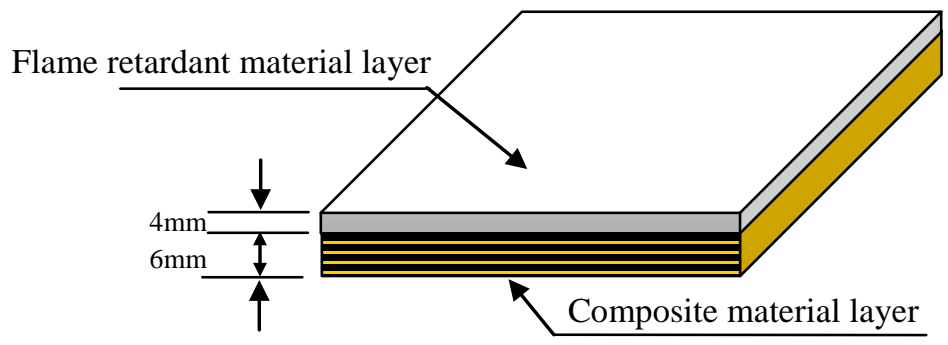

Figure 4. Sample of thermal erosion test.

Table 3. Chemical composition of zinc borate.

\begin{tabular}{ccccc}
\hline Compound & Zinc Oxide & Boric Anhydride & Water of Hydration & Impurities \\
\hline Symbol & $\mathrm{ZnO}$ & $\mathrm{B}_{2} \mathrm{O}_{3}$ & $\mathrm{H}_{2} \mathrm{O}$ & - \\
Content(\%) & 37 & 47 & 14 & 2 \\
\hline
\end{tabular}

$\mathrm{mm}$ and $20 \mathrm{~mm}$. Figure 5 shows the experimental setup of thermal erosion test, surface temperature method used to determine heat transferred through flame retardant / composite structure. Temperature was monitored, observed, measured and recorded using PC transformation card (AD) connected to K-type thermocouple.

\section{Results and Discussion}

Figure (6) represents the thermal erosion test for composite material with retardant surface layer at exposed dis- 


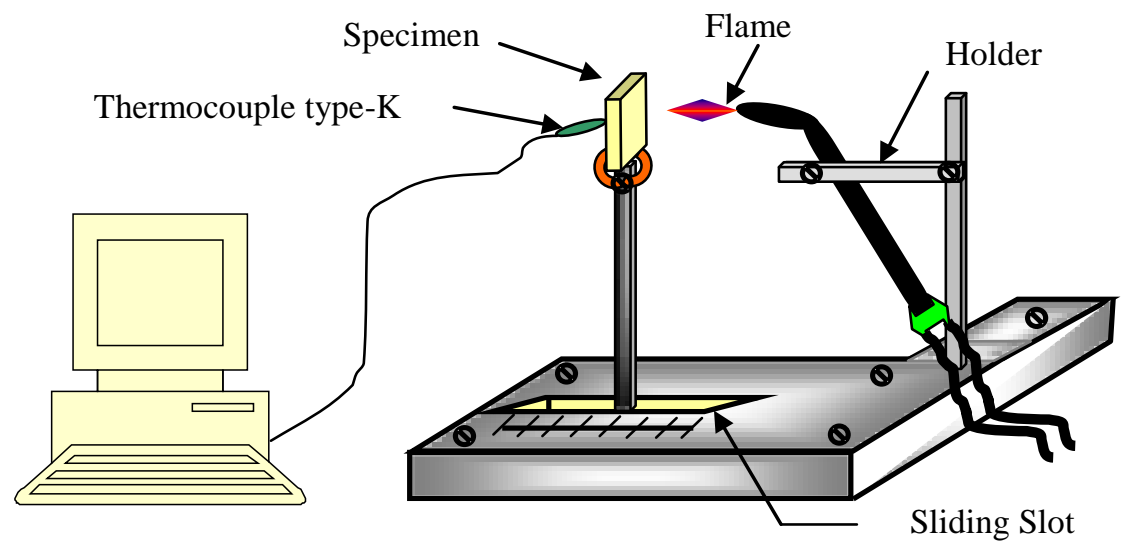

Figure 5. thermal erosion test setup.

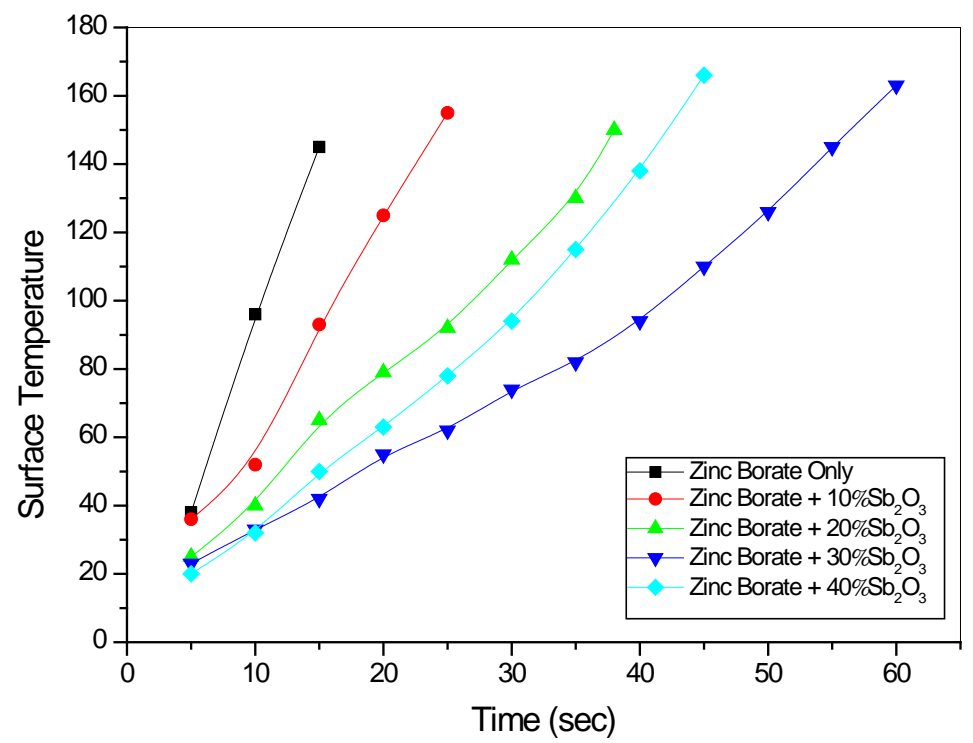

Figure 6. Flame retardancy results with exposure interval of $10 \mathbf{~ m m}$.

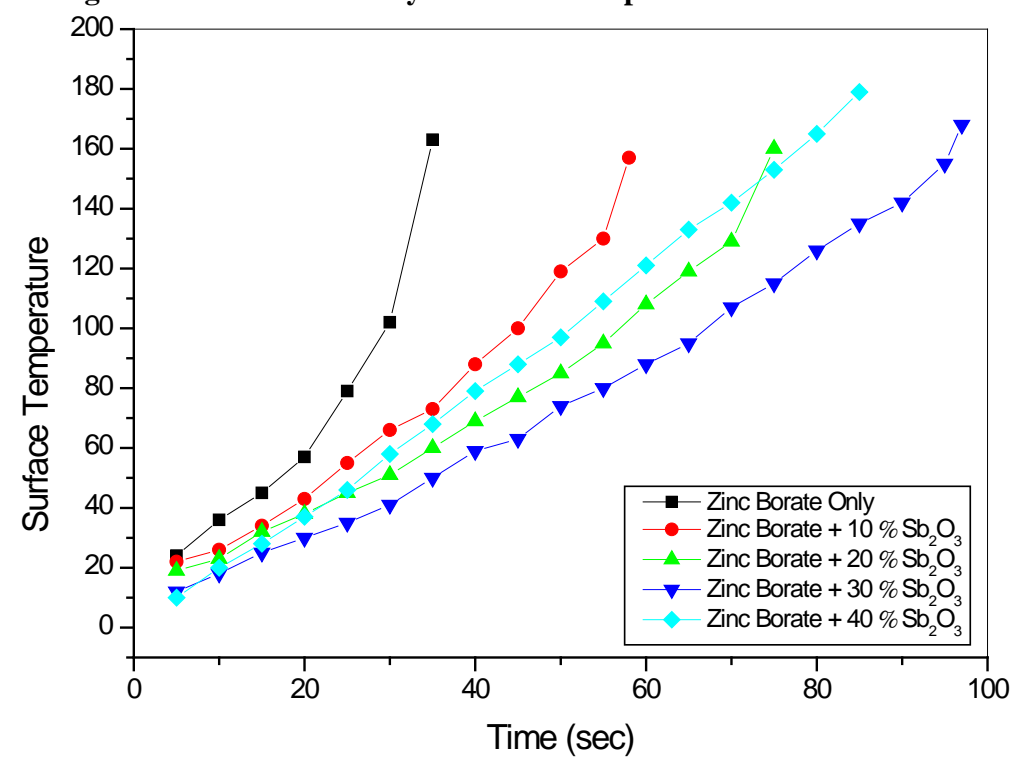

Figure 7. Flame retardancy results with exposure interval of $20 \mathrm{~mm}$. 
tance of $10 \mathrm{~mm}$. The temperature of the opposite surface to the torch begins to increase with increasing of the exposure time. During this stage zinc borate has a water of hydration in its chemical structure therefore water is released to extinguish the fire through cooling. Zinc borate will formed glassy coating layer which protect the substrate (composite material) and the fire spreading will decrease.

Zinc borate flame retardancy is increased by adding few percentage of antimony trioxide. Through the fire exposure internal structure of the antimony trioxide will be changed causing phase transformation in Zinc borate enhancing flame retardancy of composite materials as a result. This retardant action increased with the increasing of antimony trioxide percentage from $10 \%$ to $30 \%$.

Figure 7 shows the thermal erosion test for the composite material of retardant surface layer with exposure interval of $20 \mathrm{~mm}$. As a result the time required to break down the composite of flame retardant layer will increase and the combustion gaseous will reduced. There will be a less plastic to burn due to water of hydration and protected glassy coating layer comes from zinc borate and this protection will improve with addition of antimony trioxide. The mixing ratio of 3:1 (zinc borate: antimony trioxide) is obtaining the best result.

It is quite obvious from Figure 6 and 7, that the optimum mixing ratio is $3: 1$, gives the best flame retardant and shows standard layers structure stability. The opposite surface temperature reached $135^{\circ} \mathrm{C}$ after $85 \mathrm{sec}$.

The flame retardant is reduced when the mixing ratio is increased to $4: 1$. The opposite surface temperature reached $180^{\circ} \mathrm{C}$ within $85 \mathrm{sec}$.

This retardant action decreased with the increasing of antimony trioxide percentage of $40 \%$ and expecting to decrease rapidly with the increasing of antimony trioxide percentage. The $40 \%$ test shows that the surface layer was starting to decomposed and fractured after exposed to $2000^{\circ} \mathrm{C}$ flam temperature within less than one minute.

\section{Conclusions}

From this study we concluded that:
1) Using Zinc borate improved the flame retardancy of composite.

2) Adding Antimony trioxide to Zinc borate improved the layer Durability and structure.

3) The mixing ratio of 3:1 (zinc borate: antimony trioxide) is the optimum mixing ratio which is obtaining the best result.

\section{REFERENCES}

[1] J. H. Troitzsch, “Overview of Flame Retardants,” Chimica Oggi/chemistry Today, Vol. 16, January/February 1998.

[2] H. K. Tran, C. E. Johnson, D. J. Rasky and F. C. L Hui, "Phenolic Impregnated Carbon Ablators (PICA) as Thermal Protection Systems for Discovery Missions," NASA Technical Memorandum 110440, New York, April 1997.

[3] E. A. Myszak, "Use of Submicro Inorganic Flame Retardants in Polymeric Systemic,” Nyacol Nano Technologies, Ashland, 2000.

[4] A. I. Moslem, "Study Using of Antimony Trioxide Material as a Flame Retardant Material,” Engineering College, Babylon University, 2003.

[5] H. Horacek and S. Pieh, "The Importance of Intumescent Systems for Fire Protection of Plastic Materials,” Polymer International, Vol. 49, 2000.

[6] US Industry Forecasts to 2011 and 2016 "Glass Fibers," Freedonia, 2007.

[7] D. Hull, "An Introduction to Composite Materials," Cambridge University press, Cambridge, 1981.

[8] P. K. Mallick, "Fiber-Reinforced Composites: Materials, Manufacturing, and Design,” 3rd Edition, CRC Press, Taylor and Francis, November 2007.

[9] M. Langley, “Carbon Fibers in Engineering”, McGrawHill Book Company Ltd, New York, 1973.

[10] E. P. DeGarmo, J. T. Black and R. A. Kosher, "Materials and Processes in Manufacturing," 10th Edition, John Wiley \& Sons, NewYork, 2008. 